\title{
Editorial
}

\section{COVID-19 vaccine: The all-important timelines}

Sri Lanka Journal of Child Health 2021; 50(1): 01-03

DOI: http://dx.doi.org/10.4038/sljch.v50i1.9392

(Key words: COVID-19 vaccine, timeline)

A COVID-19 vaccine provides acquired immunity against COVID-19 ${ }^{1}$. Prior to COVID-19 pandemic, knowledge about the coronavirus structure was extrapolated from prior encounters with severe acute respiratory syndrome (SARS) and Middle East respiratory syndrome (MERS) ${ }^{1}$. To date, there is no safe and effective SARS vaccine ${ }^{2}$. There is also no proven MERS vaccine ${ }^{3}$. After severe acute respiratory syndrome coronavirus 2 (SARS-CoV-2) was detected in December 20194, its genetic sequence was published on 11 January 2020, triggering an international response to prepare for an outbreak and hasten the development of a vaccine ${ }^{5}$. In February 2020, World Health Organization (WHO) stated that it did not expect a vaccine against SARS-CoV-2 to become available before 18 months ${ }^{6}$. The rapid infection rate of COVID-19 worldwide during early 2020 stimulated international alliances and government efforts to urgently organize resources to make multiple vaccines on shortened timelines ${ }^{7}$.

Phase I trials test primarily for safety and preliminary dosing in a few dozen healthy subjects, while Phase II trials evaluate immunogenicity, dose levels and adverse effects of the candidate vaccine, in hundreds of people ${ }^{8,9}$. A Phase I-II trial consists of preliminary safety and immunogenicity testing and is typically randomized and placebo-controlled ${ }^{9}$. Phase III trials involve more participants at multiple sites, include a control group, and test effectiveness of vaccine to prevent the disease, while monitoring for adverse effects at optimal dose ${ }^{8,9}$. Definition of vaccine safety, efficacy, and clinical endpoints in a Phase III trial may vary between trials of different companies, such as defining degree of side effects, infection or amount of transmission, and whether the vaccine prevents moderate or severe COVID-19 infection $^{10-12}$. By mid-December 2020, 57 vaccine candidates were in clinical research, including 40 in Phase I-II trials and 17 in Phase II-III trials ${ }^{1}$.

Geopolitical issues, safety concerns for vulnerable populations, and manufacturing challenges for producing billions of doses are compressing schedules to shorten the standard vaccine development timeline, in some cases combining clinical trial steps over months, a process typically conducted sequentially over years ${ }^{13}$. In the haste to provide a vaccine on a rapid timeline for the COVID-19 pandemic, developers and governments are accepting a high risk of 'short-circuiting' or

'fast-tracking' the vaccine development $\operatorname{process}^{14}$, with one industry executive saying: "The world crisis is so big that each of us will have to take maximum risk now to put a stop to this disease" ${ }^{14}$. Multiple steps along the entire development path are evaluated, including level of acceptable toxicity of vaccine, targeting vulnerable populations, need for vaccine efficacy breakthroughs, duration of vaccination protection, special delivery systems (oral or nasal, rather than injection), dose regimens, stability and storage characteristics, emergency use authorization, all before formal licensing, optimal manufacturing for scaling to billions of doses, and dissemination of licensed vaccine ${ }^{15}$. Timelines for conducting clinical research, normally a sequential process requiring years, are being compressed into safety, efficacy, and dosing trials running simultaneously over months, potentially compromising safety assurance ${ }^{13,14}$.

A multinational collaboration, including the WHO, the Coalition for Epidemic Preparedness Innovations (CEPI), Global Alliance for Vaccination and Immunisation (GAVI), the Gates Foundation, and governments, formed the Access to COVID-19 Tools (ACT) Accelerator, to raise financial support of accelerated research and development, production, and globally-equitable access to COVID-19 tests, therapies, and licensing of vaccines, which are in a specific development programme called the COVAX Pillar ${ }^{16,17}$. The COVAX Pillar has the goal of facilitating licensure of several COVID-19 vaccines, influencing equitable pricing, and providing equal access for up to 2 billion doses by the end of 2021 to protect frontline healthcare workers and people with highrisk of COVID-19 infection, particularly in low-tomiddle income countries

Effectiveness of a new vaccine is defined by its efficacy $^{18}$. In the case of COVID-19 specifically, a vaccine efficacy of $70 \%$ may be enough to stop the pandemic, but if it has only $60 \%$ efficacy, outbreaks may continue; an efficacy of less than $60 \%$ will not provide enough herd immunity to stop the spread of the virus alone ${ }^{15}$.

On 24 June, 2020, China approved 2 inactivated virus vaccines for emergency use in high-risk occupations $^{19}$. On 11 August, 2020, Russia approved its Sputnik V vaccine for emergency use ${ }^{20}$. In the US, emergency use authorization (EUA) 
facilitates availability and use of medical countermeasures, including vaccines, during public health emergencies, like COVID-19 pandemic ${ }^{21}$. Once EUA is issued by the US Food and Drug Administration (FDA), the vaccine developer is expected to continue Phase III clinical trials to finalize safety and efficacy data, leading to application for licensure (approval) in the US ${ }^{21}$. Pfizer-BioNTech submitted EUA request to FDA for Tozinameran (mRNA Vaccine BNT162b2) on 20 November, $2020^{22}$. On 2 December, 2020, the UK Medicines and Healthcare products Regulatory Agency (MHRA) gave Pfizer-BioNTech vaccine temporary regulatory approval ${ }^{23}$, becoming the first country in the Western world to approve the use of any COVID-19 vaccine. On 11 December, 2020, the US FDA granted EUA for Pfizer-BioNTech vaccine tozinameran ${ }^{24}$. A week later, they granted EUA for Moderna vaccine (mRNA-1273), making US the first country to authorize 2 vaccines for public use $\mathrm{e}^{25}$. On $30^{\text {th }}$ December, 2020, the UK's MHRA approved use of the Oxford University /Astra Zeneca's Covid19 vaccine $^{26}$. On $31^{\text {st }}$ December, 2020, WHO granted emergency validation to Pfizer-BioNTech vaccine $^{27}$. On $3^{\text {rd }}$ January, 2021, India approved 2 Covid vaccines, the Oxford Astra Zeneca and another vaccine made by the Indian firm Bharat Biotech $^{28}$. On 22 ${ }^{\text {nd }}$ January 2021, the National Medicines Regulatory Authority (NMRA) of Sri Lanka granted Emergency Use Authorization for the Oxford Astra Zeneca vaccine ${ }^{29}$. On $28^{\text {th }}$ January 2021 India donated 500,000 doses of the AstraZeneca "Covishield" vaccine to Sri Lanka ${ }^{30}$. On 29 ${ }^{\text {th }}$ January 2021, Sri Lanka's COVID-19 vaccination drive was launched at the National Institute of Infectious Diseases ${ }^{31}$. On $17^{\text {th }}$ February 2021, WHO approved the emergency use of AstraZeneca vaccine giving the green light for it to be rolled out globally through COVAX ${ }^{32}$.

\section{References}

1. COVID-19 vaccine. Available from: C: $\backslash$ Users $\backslash$ WindowsUser $\backslash$ Documents $\backslash$ COVI D 19 vaccine $\backslash$ COVID-19 vaccine Wikipedia.html (Accessed 21.12. 2020)

2. Jiang S, Lu L, Du L. Development of SARS vaccines and therapeutics is still needed. Future Virology 2013; 8(1): 1-2. https://doi.org/10.2217/fvl.12.126 PMid: 32201503 PMCid: PMC7079997

3. Shehata MM, Gomaa MR, Ali MA, Kayali G. Middle East respiratory syndrome coronavirus: comprehensive review. Frontiers of Medicine 2016; 10(2): 120-36. https://doi.org/10.1007/s1 1684-0160430-6

PMid: 26791756 PMCid: PMC7089261
4. World Health Organization timeline COVID-19. World Health Organization. 27 April 2020. Available from: https:/www.who.int/news/item/27-042020-who-timeline---covid-19

5. Responding to Covid-19: A once-in-acentury pandemic? New England Journal of Medicine 2020; 382(18): 1677-9. https://doi.org/10.1056/NEJMp2003762 PMid: 32109012

6. Grenfell R, Drew T (14 February 2020). "Here's why the WHO says a coronavirus vaccine is 18 months away". Business Insider. Retrieved 11 November 2020

7. Update on WHO Solidarity Trial Accelerating a safe and effective COVID19 vaccine. World Health Organization. 27 April 2020. Archived from the original on 30 April 2020. Retrieved 2 May 2020.

8. Vaccine Safety - Vaccines. vaccines. gov. US Department of Health and Human Services. Archived from the original on 22 April 2020. Retrieved 13 April 2020.

9. The drug development process. U.S. Food and Drug Administration (FDA). 4 January 2018. Archived from the original on 22 February 2020. Retrieved 12 April 2020.

10. Cohen J. Pandemic vaccines are about to face the real test. Science 2020; 368 (6497): 1295-6.

https://doi.org/10.1126/science.368.649

7.1295

PMid: 32554572

11. How flu vaccine effectiveness and efficacy are measured. Centers for Disease Control and Prevention, National Center for Immunization and Respiratory Diseases, US Department of Health and Human Services. 29 January 2016. Archived from the original on 7 May 2020. Retrieved 6 May 2020.

12. Principles of epidemiology, Section 8: Concepts of disease occurrence. Centers for Disease Control and Prevention, Center for Surveillance, Epidemiology, and Laboratory Services, US Department of Health and Human Services. 18 May 2012. Archived from the original on 6 April 2020. Retrieved 6 May 2020

13. Sanger DE, Kirkpatrick DD, Zimmer C, Thomas K, Wee S (2 May 2020). "With 
Pressure Growing, Global Race for a Vaccine Intensifies". The New York Times. ISSN 0362-4331. Archived from the original on 11 May 2020. Retrieved 2 May 2020.

14. Steenhuysen J, Eisler P, Martell A, Nebehay S (27 April 2020). "Special Report: Countries, companies risk billions in race for coronavirus vaccine". Reuters. Archived from the original on 15 May 2020. Retrieved 2 May 2020

15. Gates B (30 April 2020). "The vaccine race explained: What you need to know about the COVID-19 vaccine". The Gates Notes. Archived from the original on 14 May 2020. Retrieved 2 May 2020.

16. What is the ACT Accelerator? World Health Organization. 2020. Archived from the original on 25 September 2020. Retrieved 29 August 2020.

17. What is COVAX? GAVI. 1 September 2020. Retrieved 11 December 2020.

18. Zimmer, Carl (20 November 2020). "2 Companies Say Their Vaccines Are 95\% Effective. What Does That Mean? You might assume that 95 out of every 100 people vaccinated will be protected from Covid-19. But that's not how the math works". The New York Times. Retrieved 21 November 2020.

19. WHO 'backed China's emergency use' of experimental Covid-19 vaccines South China Morning Post. 25 September 2020. Archived from the original on 26 September 2020. Retrieved 26 September 2020.

20. Kramer AE (19 September 2020). "Russia Is Slow to Administer Virus Vaccine Despite Kremlin's Approval". The New York Times. ISSN 0362-4331. Archived from the original on 27 September 2020. Retrieved 28 September 2020.

21. Emergency Use Authorization for Vaccines Explained U.S. Food and Drug Administration. 20 November 2020. Retrieved 20 November 2020.

22. Pfizer and BioNTech to Submit Emergency Use Authorization Request Today to the U.S. FDA for COVID-19 Vaccine". Pfizer (Press release). 20 November 2020. Retrieved 20 November 2020.

23. Conditions of Authorisation for Pfizer/BioNTech COVID-19 vaccine. Medicines and Healthcare products
Regulatory Agency (MHRA). 3 December 2020. Retrieved 19 December 2020.

24. Thomas $\mathrm{K}$, LaFraniere $\mathrm{S}$, Weiland $\mathrm{N}$, Goodnough A, Haberman M (12 December 2020). "F.D.A. clears Pfizer vaccine and millions of doses will be shipped right away". New York Times. Retrieved 12.12. 2020.

25. FDA takes additional action in fight against COVID-19 by issuing emergency use authorization for second COVID-19 vaccine". U.S. Food and Drug Administration (Press release). Retrieved 18.12. 2020.

26. Oxford University/AstraZeneca vaccine authorised by UK medicines regulator. Available from:

https://www.gov.uk/government/news/oxfor d-universityastrazeneca-vaccine-authorisedby-uk-medicines-regulator

27. WHO grants 'emergency validation' to Pfizer-BioNTech vaccine. Available from: https://uk.news.yahoo.com/grantsemergency-validation-pfizer-biontech003711370.html

28. India approves 2 Covid vaccines. Available from:

https://www.dailymail.co.uk/news/article9108573/India-approves-TWO-Covidvaccines-giving-green-light-Oxford-AstraZeneca-jab.html

29. https://www.oxfordmail.co.uk/news/national /19031670.sri-lanka-approves-astrazenecavaccine-amid-health-system-collapsewarning/

30. http://www.dailynews.lk/2021/01/29/local/2 40137/india $\%$ E2\%80\%99s-free-covishieldjabs-arrive

31. https://www.msn.com/en$\mathrm{xl} /$ news/other/covid-19-vaccination-drivelaunched-at-idh/ar-BB1ddKso

32. https://www.msn.com/en$\mathrm{xl} /$ news/other/who-approves-covishield-foremergency-use/ar-BB1dJR39

G N Lucas iD https://orcid.org/0000-0002-4005-5618 Joint Editor

The author declares that there are no conflicts of interest

Open Access Article published under the Creative

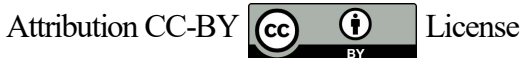

